\title{
A study to examine the relationship between metritis severity and depletion of oxytetracycline in plasma and milk after intrauterine infusion
}

\author{
P. J. Gorden, ${ }^{* 1}$ J. A. Ydstie, ${ }^{*}$ M. D. Kleinhenz, ${ }^{*}$ L. W. Wulf, ${ }^{*} \dagger$ R. Gehring, $\ddagger$ C. J. Lee, ${ }^{*} \dagger^{2}$ C. Wang, ${ }^{*}$ \\ and J. F. Coetzee ${ }^{*} \dagger^{1}$ \\ *Veterinary Diagnostic and Production Animal Medicine, College of Veterinary Medicine, and \\ †Pharmacology Analytical Support Team, Veterinary Diagnostic Laboratory, College of Veterinary Medicine, lowa State University, Ames 50011 \\ łDepartment of Anatomy and Physiology, College of Veterinary Medicine, Kansas State University, Manhattan 66502
}

\begin{abstract}
Metritis is a frequent problem in postpartum dairy cows. Intrauterine therapy with the antimicrobial oxytetracycline (OTC) is often used, although this therapy has not been shown to be superior to systemic therapy. The objectives of this study were to (1) determine the plasma and milk concentrations of OTC following intrauterine infusion in postpartum dairy cows with varying degrees of metritis severity; (2) determine the depletion time of OTC in an attempt to provide veterinarians withdrawal guidelines, should they use this therapy; and (3) correlate metritis severity scores with OTC concentrations in plasma and milk. Our hypothesis was that cows with more severe metritis would have higher OTC concentrations in milk following intrauterine therapy. Thirty-two cows were selected to participate in the study after farm personnel had determined that they had metritis based on evaluation of vaginal discharge between 4 and 14 DIM, in accordance with the farm's treatment protocols. Metritis scores (1-4) were assigned based on a published scheme: 1 represented yellow-to-orange thick discharge or translucent mucus with no fetid smell; 2 represented blood-tinged vaginal mucus, slightly watery, with little or no fetid smell; 3 represented red to red/brown watery discharge with moderate fetid smell; and 4 represented red to red/ brown watery discharge containing pieces of placenta and an intense fetid smell. Trial cows received a single treatment of $4 \mathrm{~g}$ of OTC (approximately $6.7 \mathrm{mg} / \mathrm{kg}$ ) via intrauterine infusion. Blood samples were collected over $96 \mathrm{~h}$, and milk samples were collected before intrauterine therapy and 3 times a day for $4 \mathrm{~d}$ following infusion. Following treatment, OTC rapidly diffused
\end{abstract}

\footnotetext{
Received January 28, 2016.

Accepted June 27, 2016.

${ }^{1}$ Corresponding authors: pgorden@iastate.edu and hcoetzee@ iastate.edu

${ }^{2}$ Current address: Division of Food and Environmental Sciences, Wonkwang University, Iksan, Jeonbuk, South Korea.
}

to plasma and subsequently to milk. Maximum OTC concentrations in plasma and milk occurred within the first $24 \mathrm{~h}$ following intrauterine infusion, and 25 of the 32 cows had detectable OTC concentrations in milk at $4 \mathrm{~d}$ after intrauterine infusion. Cows with clinical metritis (metritis severity scores of 3 or 4 ) at the initiation of treatment were significantly and positively correlated with higher milk OTC concentrations at the second [time $(\mathrm{T}) 9 \mathrm{~h} ; \mathrm{r}=0.43$ ], fourth $(\mathrm{T} 25 \mathrm{~h} ; \mathrm{r}=$ 0.42 ), and fifth milking following treatment (T33 h; r $=0.38$ ) compared with cows with normal vaginal discharge. We also observed a positive correlation between initial metritis score and milk maximum concentration $(\mathrm{r}=0.36)$ and milk area under the concentration curve $(\mathrm{r}=0.36)$. Given that intrauterine administration of OTC is an extra-label therapy, dairy producers should consult with their veterinarian to ensure that milk is being tested at or below the established tolerance for OTC. This will ensure that violative drug residues do not enter the human food supply.

Key words: bovine metritis, oxytetracycline, pharmacokinetics, drug residues

\section{INTRODUCTION}

Bacterial contamination of the uterus occurs in $90 \%$ or more of dairy cows during the first week after calving (Sheldon and Dobson, 2004). Interestingly, bacterial contamination of the postpartum uterus has been described as dynamic, with contamination, clearance, and recontamination occurring throughout the postpartum period (Griffin et al., 1974). The dynamic status of the intrauterine environment results in much lower rates of clinical metritis and endometritis than would be expected given the high levels of bacterial infection in the first week postpartum. The prevalence of metritis in postpartum cows can range from 18 to $33 \%$; however, accurate estimates are difficult to obtain due to inconsistencies in clinical disease definitions among modern dairy farms (Markusfeld, 1987; Drillich et al., 2001; Benzaquen et al., 2007). Trueperella 
pyogenes, Escherichia coli, Fusobacterium necrophorum, and Prevotella melaninogenicus are the bacteria most commonly isolated from cases of clinical metritis. These bacteria are distributed throughout all layers of the uterus during cases of clinical metritis, making parenteral therapy a more effective choice for treatment (Sheldon and Dobson, 2004).

Current treatment practices on US dairy farms for common diseases, including metritis, are not well documented in the literature. Recently, our research group conducted a survey of 83 Midwest dairy farms to document treatment practices on these farms. The survey found that $58 \%$ of farms practiced at least some intrauterine therapy for metritis, and just over half of these farms used oxytetracycline (OTC) in their infusions (P. J. Gorden, unpublished data). Although intrauterine antimicrobial therapy is used on dairy farms in some parts of the United States, the results of studies designed to assess improvements in uterine health or financial outcomes have not shown benefits from the use of intrauterine therapy alone or in combination with systemic treatments (Smith et al., 1998; Drillich et al., 2001). However, repeated intrauterine therapy with chlortetracycline has been shown to be superior to no treatment (Goshen and Shpigel, 2006). As well, systemic absorption of antibiotics following intrauterine infusion has been reported. This can result in costly milk discard and is a risk for antibiotic residue in bulk tank milk intended for human consumption (Dinsmore et al., 1996). Intrauterine antibiotic administration in cattle in the United States is considered an extra-label therapy and is governed by the Animal Medicinal Drug Use Clarification Act (21CFR530; US FDA, 1996). Under these regulations, the prescribing veterinarian must determine if extra-label therapy is justified and allowable. The prescribing veterinarian is also responsible for specification of a withdrawal time for milk and meat that ensures that products from treated cows are below the tolerance levels for antimicrobial residues, as well as properly documenting extra-label therapy. Previous trials have also reported considerable variation in the depletion profile of drugs from milk following intrauterine infusion (Kaneene et al., 1986; Anderson et al., 1995; Dinsmore et al., 1996). Such variation may be associated with the severity of metritis and resulting inflammation, which could have an effect on drug absorption.

Designing a system to assess the severity of metritis in postpartum cows is a subject of debate in the literature, and no gold standard has been established (Wenz et al., 2011; Sannmann et al., 2012; de Boer et al., 2014). Some suggest that the severity of metritis should be graded based on abnormal character and odor of the vaginal discharge, along with a rectal temperature $>39.5^{\circ} \mathrm{C}$ (Sheldon et al., 2009). Others suggest that a large percentage of animals with severe metritis will be missed when including rectal temperature $>39.0^{\circ} \mathrm{C}$ (Palenik et al., 2009) or $>39.3^{\circ} \mathrm{C}$ (Benzaquen et al., 2007) as a diagnostic criterion. In cows with endometritis, the clinical evaluation of the character and odor of vaginal discharge has been associated with pathogenic bacterial load (Williams et al., 2005). Because farm personnel were using transrectal uterine massage to express uterine contents and grade the clinical severity of metritis without using rectal temperature, we modified previously described uterine severity scoring systems (Benzaquen et al., 2007; Sheldon et al., 2009) to assess metritis severity in trial cows.

Before the 2015 Pasteurized Milk Ordinance (PMO), scheduled testing of drugs other than $\beta$-lactams was not required for milk marketed as grade $\mathrm{A}$ in the United States (US FDA, 2013). However, although it is not required, dairy processors can still test tanker milk for the presence of tetracycline-class drugs if they wish. At the 2015 National Conference on Interstate Milk Shipments (NCIMS), proposal 211 was passed requiring the development of a more comprehensive milk residue-testing program under Appendix N of the PMO, starting with the 2015 version (US FDA, 2015a). As a result, regular screening for drugs such as OTC could be undertaken for regulatory purposes in the near future.

The objective of this study was to use highly sensitive laboratory technology to determine the plasma and milk concentrations of OTC following intrauterine infusion in postpartum dairy cows. We also hoped to characterize OTC depletion from plasma and milk to better determine milk withdrawal times and correlate OTC concentrations throughout the study with metritis severity scores. We hypothesized that variability in distribution and elimination of OTC from the uterus to plasma and milk would be associated with the severity of metritis, as assessed by metritis scores. Specifically, we postulated that cows experiencing more severe metritis would have higher plasma and milk OTC concentrations than less severely affected cows.

\section{MATERIALS AND METHODS}

\section{Animals and Eligibility Criteria}

Cows were housed in a privately owned, commercial confinement dairy facility with sand-bedded free stalls and manger headlocks. Our protocol complied with the requirements of Iowa State University's Institutional Animal Care and Use Committee. The trial herd had a 305-d mature-equivalent milk production of 10,935 $\mathrm{kg}$. During the pre- and postpartum periods, cows were fed a TMR once per day that was formulated to meet 
or exceed the NRC (2001) requirements and provided water ad libitum. When the trial was initiated, the herd was made up of $32 \%$ primiparous cows. Recently fresh cows, up to approximately 30 DIM, were housed in 2 separate fresh pens, with one pen for recently fresh primiparous cows and another pen for recently fresh multiparous cows. Farm hospital personnel performed daily observations of the fresh cows while cows were in headlocks. Cows in the fresh pens between 4 and 14 DIM underwent a rectal exam to assess uterine health. Additionally, feed intake, udder fill, and attitude were used to determine which cows should be examined more closely for other disease conditions.

Cows were milked 3 times daily at 0900, 1700, and 0100 h. Daily milk weights were recorded using the onfarm milk meters and computer system (GEA Farm Technologies, Naperville, IL).

\section{Study Design}

A foremilk sample was collected from 1 of the rear quarters of all postpartum cows on d 2 after parturition to be used for a baseline level of OTC should the cow later undergo intrauterine therapy for metritis. After collection, milk samples were immediately frozen at $-20^{\circ} \mathrm{C}$ on the farm until they were transported to the laboratory following initiation of therapy.

Cows that had a retained placenta (RP) at 4 DIM were not eligible in the trial. Cows that had been treated for other infectious conditions or for ketosis following parturition were also excluded. After treatment with intrauterine OTC, any cow that was treated with additional drugs or with a second dose of intrauterine OTC was removed from the trial.

Every day, all cows in the fresh pens that were either 4 , 7, or 10 DIM underwent a rectal exam to determine uterine health. During this exam, the uterus was manipulated transrectally to express uterine contents and determine the presence of metritis. On days when cows were not scheduled to undergo a rectal exam, they could still be enrolled if they were determined to have metritis during the routine assessment of all cows in the pen. Cows were selected for further evaluation if they appeared to be sick based on visual observations of feed intake, attitude, and udder fill. Cows with metritis as diagnosed by farm personnel based on abnormal appearance of the vaginal discharge, were given $4 \mathrm{~g}$ (approximately $6.7 \mathrm{mg} / \mathrm{kg}$ ) of OTC as a $20 \%$ solution marketed for parenteral injection (20 mL of Agrimycin 200; AgriLabs, St. Joseph, MO) by intrauterine infusion via a plastic pipette passed through the cervix. Cows could also receive ceftiofur hydrochloride (Excenel RTU EZ; Zoetis, Florham Park, NJ) before or at the time of intrauterine therapy, at approximately $2.2 \mathrm{mg}$ of ceftiofur equivalents via i.m. injection for $3 \mathrm{~d}$ if farm personnel determined that the cow needed additional therapy. Farm personnel estimated cow weights to determine ceftiofur dosage. Study personnel provided no input on disease diagnosis, disease definitions, or treatment decisions.

At treatment, study personnel assigned metritis scores to each cow using a modification of previously described scoring systems (Benzaquen et al., 2007; Sheldon et al., 2009; Table 1) based on the appearance and smell of vaginal discharge and without knowledge of rectal temperature. The metritis scoring system was designed to differentiate cows with clinically normal vaginal discharge (score 1 or 2 ) from cows with vaginal discharge consistent with clinical metritis (score 3 or 4). Metritis scores were reassigned daily for $4 \mathrm{~d}$ following the initial treatment.

Foremilk samples were collected daily at 2 of 3 milkings (0900 and $1700 \mathrm{~h}$ milkings) for $4 \mathrm{~d}$ after treatment to determine OTC residues. The first posttreatment milk collection was scheduled to occur within $1 \mathrm{~h}$ of treatment, and the second sample was collected $8 \mathrm{~h}$ later. After collection, milk samples were immediately frozen at $-20^{\circ} \mathrm{C}$, transported to the laboratory, and stored at $-20^{\circ} \mathrm{C}$ until analysis.

Blood samples for plasma harvest were collected via the coccygeal vein in heparin tubes (Becton, Dickinson and Co., Franklin Lakes, NJ) immediately after intrauterine infusion and once daily for $4 \mathrm{~d}$ to assess circulating OTC concentration. After collection, blood samples were centrifuged, and the plasma fraction was harvested and frozen at $-20^{\circ} \mathrm{C}$. Samples were transported frozen and stored at the laboratory at $-20^{\circ} \mathrm{C}$ until analysis.

Table 1. Metritis scoring system ${ }^{1}$

\begin{tabular}{ll}
\hline Description of vaginal discharge & Score \\
\hline Yellow to orange thick discharge or translucent mucus; no fetid smell & 1 \\
Blood-tinged vaginal mucus, slightly watery; little or no fetid smell & 2 \\
Red to red/brown watery discharge; moderate fetid smell & 3 \\
Red to red/brown watery discharge with or without pieces of placenta; intense fetid smell & 4 \\
\hline${ }^{1}$ Vaginal mucus was graded daily for character, color, and smell using modified descriptions adopted from \\
Sheldon et al. (2009) and Benzaquen et al. (2007).
\end{tabular}




\section{Plasma OTC Concentration Analysis}

Plasma concentrations of OTC were determined using high-pressure liquid chromatography (Surveyor Pump and Autosampler; Thermo Scientific, San Jose, CA) coupled with mass spectrometry (TSQ Discovery Max; Thermo Scientific). Plasma samples, plasma spikes, plasma quality control samples, and bovine plasma blanks $(200 \mu \mathrm{L})$ were treated with $100 \mu \mathrm{L}$ of $1.0 M$ trichloroacetic acid (TCA) to precipitate plasma proteins. Before addition of the TCA, $10 \mu \mathrm{L}$ of $10 \mathrm{ng} /$ $\mu \mathrm{L}$ demeclocycline, an internal standard, was added to all samples. The samples were vortexed for $5 \mathrm{~s}$ after the addition of TCA and centrifuged for $20 \mathrm{~min}$ at 2,000 $\times$ $g$ to sediment the protein pellet. Following centrifugation, $200 \mu \mathrm{L}$ of the supernatant was pipetted off into autosampler vials equipped with $300-\mu \mathrm{L}$ glass inserts. Then, $50 \mu \mathrm{L}$ of $2.5 \%$ ammonium hydroxide in $25 \%$ acetonitrile in water was added to each inset and the vials capped and vortexed. The samples were centrifuged at $2,000 \times g$ for $20 \mathrm{~min}$ before analysis.

For analysis with liquid chromatography coupled with mass spectrometry (LC-MS), the injection volume was set to $25 \mu \mathrm{L}$. The mobile phases consisted of (A) $0.1 \%$ formic acid in water and (B) $0.1 \%$ formic acid in acetonitrile at a flow rate of $0.25 \mathrm{~mL} / \mathrm{min}$. The mobile phase began at $7.5 \% \mathrm{~B}$, with a linear gradient to $95 \% \mathrm{~B}$ in $7.00 \mathrm{~min}$, which was maintained for 1.5 min, followed by re-equilibration to $7.5 \%$ B. Separation was achieved with a KinetexXB C18 column (100 mm $\times 2.1 \mathrm{~mm}, 2.6-\mu \mathrm{m}$ solid core particles; Phenomenex, Torrance, CA) and maintained at $45^{\circ} \mathrm{C}$. The OTC and demeclocycline were eluted at 4.08 and $4.37 \mathrm{~min}$, respectively. Multiple reaction monitoring of at least 3 transitions of the pseudomolecular ions of OTC $(\mathrm{m} / \mathrm{z}$ 445.16) and demeclocycline $(m / z 465.13)$ was used for analyte detection. The transitions monitored for OTC were ions at 98.1, 154.0, 410.1, and 427.1. The 3 transition ions for demeclocycline were 154.0, 289.0, and 448.1. The total ion counts for both analytes were used for quantitation. Sequences consisting of plasma blanks, calibration spikes, quality control samples, and bovine plasma samples were batch-processed using a method developed in the Xcalibur software (Thermo Scientific). The processing method automatically identified and integrated each peak in each sample and calculated the calibration curve based on a weighted $(1 / \mathrm{x})$ quadratic fit. Plasma concentrations of OTC in unknown samples were calculated using the Xcalibur software based on the calibration curve. Results were then viewed in the Quan Browser portion of the Xcalibur software. Eleven calibration spikes were prepared in blank bovine plasma, covering a concentration range of 1 to 2,000 $\mathrm{ng} / \mathrm{mL}$. Calibration curves exhibited a correlation co- efficient (r) exceeding 0.995 across the concentration range. Quality control samples at 15, 150, and 1,500 $\mathrm{ng} / \mathrm{mL}$ were within a tolerance of $\pm 15 \%$ of the nominal value. The limit of detection was $1.5 \mathrm{ng} / \mathrm{mL}$ (ppb) and the limit of quantitation of the analysis was $5.0 \mathrm{ng} / \mathrm{mL}$.

\section{Milk OTC Concentration Analysis}

After thawing at room temperature, milk samples, milk spikes, and milk quality control samples $(1.0 \mathrm{~mL}$ in 16- $\times 150-\mathrm{mm}$ glass screw-top tubes) were fortified with the internal standard demeclocycline $(10 \mu \mathrm{L}$ of a $10 \mathrm{ng} / \mu \mathrm{L}$ solution). An equivalent volume of ultra-pure water was added to each sample and vortexed. Then, $0.5 \mathrm{~mL}$ of $0.2 M$ disodium EDTA was added to each sample and vortexed. Last, $5 \mathrm{~mL} 0.5 \%$ acetic acid in acetonitrile was added to each sample and vortexed. Next, $0.5 \mathrm{~g} \pm 0.1 \mathrm{~g}$ of sodium sulfate fractions were premeasured and added to each sample simultaneous to vigorous vortexing to avoid clumping during salt-out. Tubes were capped tightly and mixed by inversion for $5 \mathrm{~min}$ at $300 \mathrm{rpm}$, and then centrifuged at 2,000 $\times \mathrm{g}$ for $10 \mathrm{~min}$. The top organic layer was transferred to a clean $16-\times 100-\mathrm{mm}$ glass tube and evaporated under a stream of nitrogen at $48^{\circ} \mathrm{C}$ to a total volume of approximately $0.5 \mathrm{~mL}$. Then, $1 \mathrm{~mL}$ of $0.1 \mathrm{M}$ ammonium acetate buffer ( $\mathrm{pH}$ 4.5) was added to each reduced sample.

A solid-phase extraction cleanup followed, using a positive-pressure manifold (UCT Inc., Bristol, PA). Strata-X cartridges $(60 \mathrm{mg} / 3 \mathrm{~mL}$; Phenomenex) were conditioned and equilibrated sequentially with $2 \mathrm{~mL}$ of methanol, $2 \mathrm{~mL}$ of ultra-pure water, and $1 \mathrm{~mL}$ of 0.1 $M$ ammonium acetate buffer ( $\mathrm{pH} 4.5$ ). The buffered samples were loaded onto the cartridges under gravitational flow. The cartridges were washed with $5 \%$ acetonitrile in $0.5 \mathrm{~mL}$ of $1 \%$ formic acid and dried under full vacuum for $5 \mathrm{~min}$. A $0.5-\mathrm{mL}$ hexane wash followed, with an additional 5-min dry under full vacuum. Target analytes were eluted with $2 \times 1$-mL fractions of 70:30 acetonitrile to methanol. Eluent was reduced to dryness under a stream of nitrogen at $48^{\circ} \mathrm{C}$. Next, $150 \mu \mathrm{L}$ of $25 \%$ acetonitrile in water was added to reconstitute the sample residues and vortexed briefly. Then, $50 \mu \mathrm{L}$ of ultra-pure water was added and vortexed briefly. The entire reconstituted samples were transferred to labeled autosampler vials equipped with glass inserts for analysis by LC-tandem MS.

Milk concentrations of OTC were determined using high-pressure liquid chromatography (Accela Pump and Autosampler; Thermo Scientific) coupled with tandem MS (LTQ XL; Thermo Scientific). The sample injection volume was set to $25 \mu \mathrm{L}$. The mobile phases consisted of (A) $0.1 \%$ formic acid in water and (B) $0.1 \%$ formic 
acid in acetonitrile at a flow rate of $0.225 \mathrm{~mL} / \mathrm{min}$. The mobile phase began at $10 \% \mathrm{~B}$ with a linear gradient to $95 \% \mathrm{~B}$ at $6.5 \mathrm{~min}$, which was maintained for $2 \mathrm{~min}$, followed by re-equilibration to $10 \% \mathrm{~B}$. Separation was achieved with a C18 column (Titan-C18, $100 \mathrm{~mm} \times$ $2.1 \mathrm{~mm}, 1.9-\mu \mathrm{m}$ particles, Phenomenex) maintained at $40^{\circ} \mathrm{C}$. The OTC and demeclocycline were eluted at 3.63 and $3.99 \mathrm{~min}$, respectively. Using ion trap MS and electrospray ionization in positive polarity mode, the quantifying ions for OTC were 337.10 and $381.10 \mathrm{~m} / z$ and for demeclocycline were 154.05 and $289.04 \mathrm{~m} / z$, respectively. Sequences consisting of milk blanks, calibration spikes, quality control samples, and bovine milk samples were batch-processed using a method developed in the Xcalibur software (Thermo Scientific). Milk concentrations of OTC in unknown samples were calculated by the Xcalibur software based on the calibration curve. Results were then viewed in the Quan Browser portion of the Xcalibur software. Eleven calibration spikes were prepared in bovine milk covering a concentration range of 1 to $2,000 \mathrm{ng} / \mathrm{mL}$ (i.e., ppb). Quality control samples were prepared at concentrations of 7.5, 75, and $750 \mathrm{ng} /$ $\mathrm{mL}$. Quality control samples were prepared in duplicate with each set of samples. Calibration curves exhibited a correlation coefficient (r) exceeding 0.99 across the entire concentration range. The quality control samples were accepted as passing within $15 \%$ of their nominal values. The limit of detection was $1.5 \mathrm{ng} / \mathrm{mL}$, and the limit of quantification was $5.0 \mathrm{ng} / \mathrm{mL}$.

\section{Pharmacokinetic Analysis}

Drug concentrations in plasma and milk over time were described by noncompartmental analysis using a commercial software program (Kinetica; Thermo Scientific). The maximum concentration (Cmax) and time at maximum concentration (Tmax) for plasma and milk were calculated directly from the raw data. The area under the concentration curve (AUC) was calculated using the linear trapezoidal rule with linear interpolation.

\section{Data Analysis}

We explored the relationship between plasma and milk pharmacokinetic parameters and metritis scores using statistical software (SAS 9.4; SAS Institute Inc., Cary, NC). Drug concentrations had distributions that were right-skewed with long tails; therefore, we used nonparametric methods to determine significance between the variables. We calculated Spearman's rank correlation coefficients between variables and tested for significance using the CORR procedure in SAS. The variables assessed were DIM at treatment initiation, lactation number, OTC concentration in milk at each time point sampled, milk OTC Cmax, milk OTC Tmax, milk OTC AUC, OTC concentration in plasma at each time point sampled, plasma OTC Cmax, plasma OTC Tmax, plasma OTC AUC, metritis severity score at each time point, average metritis severity score, maximum metritis severity score, normal metritis score (1 or 2) versus abnormal metritis score (3 or 4 ), presence or absence of an RP at $24 \mathrm{~h}$ after calving, and ceftiofur use. Presence of an RP and use of ceftiofur were included as binary variables. Statistical significance was established when $P<0.05$.

\section{RESULTS}

Thirty-two cows were enrolled in the study between 4 and 14 DIM (mean \pm SD $6.8 \pm 2.8)$. The mean $( \pm$ SD) lactation number was $2.3 \pm 1.4$ (range $1-5$ ), and 15 study animals were primiparous. Five cows had an RP the day after parturition, but all cows had passed the placenta before intrauterine therapy. No cow had milk OTC concentrations above the limit of detection before enrollment, and OTC was detected at all time points in milk from 18 of the 32 cows. Eleven cows had OTC in the plasma when the first plasma sample was collected in association with intrauterine therapy at time $0 \mathrm{~h}$ (T0; range 5.3-69.9 ng/mL). Plasma OTC pharmacokinetic values for all cows are shown in Table 2. Plasma OTC concentrations for each time point for cows with a normal initial metritis severity score (1 or 2 ) versus cows with an abnormal initial score (3 or 4 ) are displayed in Figure 1 . The mean $( \pm \mathrm{SE})$ Cmax of OTC in plasma was $220.6 \pm 31.0 \mathrm{ng} / \mathrm{mL}$ and was recorded at a Tmax of $23.2 \pm 1.3 \mathrm{~h}$ after intrauterine infusion. The mean $( \pm \mathrm{SE})$ plasma AUC was 8,744.8 $\pm 1,335.6 \mathrm{~h} \times$ $\mathrm{ng} / \mathrm{mL}$. Milk OTC pharmacokinetic values for all cows are shown in Table 2. Milk OTC concentrations for each time point for cows with an initial metritis severity score of 1 or 2 versus cows with an initial score of 3 or 4 are shown in Figure 2. Four milk samples were lost during transport; those time points were not included in the data analysis. The mean $( \pm \mathrm{SE})$ Cmax of OTC in milk was $136.1 \pm 19.1 \mathrm{ng} / \mathrm{mL}$ and was recorded at a Tmax of $22.0 \pm 1.8 \mathrm{~h}$ after intrauterine infusion. The mean $( \pm \mathrm{SE})$ milk AUC was $5,961.9 \pm 945.6 \mathrm{~h} \times \mathrm{ng} /$ $\mathrm{mL}$.

At the initiation of therapy, 13 of the 32 cows (40\%) had a metritis severity score of $1(\mathrm{n}=3)$ or $2(\mathrm{n}=$ 10). Eight cows had an initial metritis severity score of 3 , and 11 had an initial score of 4 . Higher metritis severity scores at the initiation of treatment were positively correlated with higher milk OTC concentrations at second milking $(\mathrm{T} 9 \mathrm{~h})$ following treatment $(\mathrm{r}=0.46$; $P=0.01)$. We also observed a tendency for a positive 
Table 2. Single-dose plasma and milk pharmacokinetic parameters after a 4-g intrauterine infusion of oxytetracycline hydrochloride in postpartum cows; results are presented as arithmetic mean $( \pm \mathrm{SE})$ for oxytetracycline

\begin{tabular}{lcc}
\hline Parameter $^{1}$ & Plasma & Milk \\
\hline Cmax $(\mathrm{ng} / \mathrm{mL})$ & $220.6( \pm 31.0)$ & $136.1( \pm 19.1)$ \\
Tmax $(\mathrm{h})$ & $23.2( \pm 1.3)$ & $22.0( \pm 1.8)$ \\
AUC $(\mathrm{h} \times \mathrm{ng} / \mathrm{mL})$ & $8,744.8( \pm 1,335.6)$ & $5,961.9( \pm 945.6)$ \\
\hline
\end{tabular}

${ }^{1} \mathrm{Cmax}=$ maximum plasma concentration for the first dose; Tmax $=$ time to $\mathrm{Cmax} ; \mathrm{AUC}=$ area under the concentration curve from 0 to $24 \mathrm{~h}$.

correlation with initial metritis severity score and milk OTC concentration at the fourth $(\mathrm{T} 25 \mathrm{~h})(\mathrm{r}=0.32 ; P$ $=0.076)$ and fifth $(\mathrm{T} 33 \mathrm{~h})(\mathrm{r}=0.30 ; P=0.098)$ milking following treatment, as well as at higher milk Cmax OTC concentrations $(\mathrm{r}=0.30 ; P=0.09)$. We observed no correlation between initial metritis score and milk OTC concentrations at the conclusion of the study ( $\mathrm{r}$ $=-0.13 ; P=0.46)$. When initial severity score was considered as either clinically normal (score 1 or 2 ) or abnormal (score 3 or 4 ), an abnormal score was positively correlated with higher milk OTC concentrations at the second (T9 $\mathrm{h} ; \mathrm{r}=0.43 ; P=0.006$ ), fourth (T25 $\mathrm{h} ; \mathrm{r}=0.42 ; P=0.018)$, and fifth (T33 h; $\mathrm{r}=0.38 ; P=$ $0.032)$ milkings following treatment. We also observed a positive correlation between an initial abnormal score and milk Cmax $(\mathrm{r}=0.36 ; P=0.042)$ and milk AUC (r $=0.36 ; P=0.042$ ).

Nine of the 31 cows enrolled in the trial had an RP at $24 \mathrm{~h}$ after calving. All cows expelled their placenta before 4 DIM and were therefore eligible for study enrollment. Presence of an RP $24 \mathrm{~h}$ after calving was

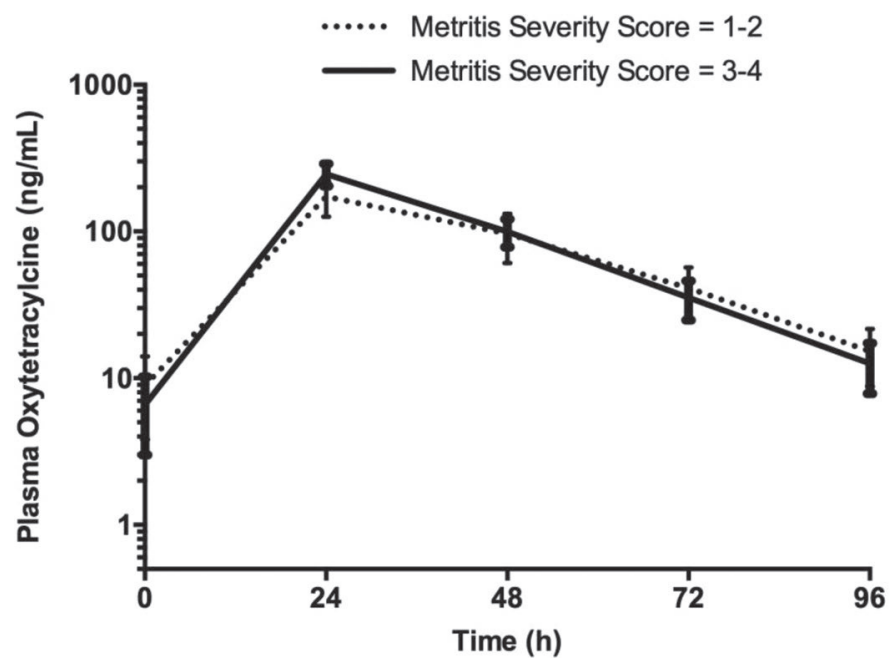

Figure 1. Log transformations of mean $( \pm \mathrm{SE})$ of plasma oxytetracycline concentration for cows with initial metritis severity score 1 or 2 versus cows with severity score 3 or 4 following a single intrauterine administration of $4 \mathrm{~g}$ of oxytetracycline hydrochloride. positively correlated with lactation number $(\mathrm{r}=0.36$; $P=0.041)$ and negatively correlated with milk Cmax $(\mathrm{r}=-0.36 ; P=0.044)$. No other parameters showed significant correlations with the presence of an RP 24 $\mathrm{h}$ after calving.

Twenty-one of the trial cows received ceftiofur therapy, $8(38 \%)$ of which had a metritis severity score of 1 or 2 . We observed no significant correlations between ceftiofur use and the presence of an abnormal uterine score $(3$ or 4$)$ at the initiation of the trial $(\mathrm{r}=0.07 ; P=$ $0.70)$. We observed no significant correlations between any of the other variables examined. No trial cows treated with intrauterine OTC received any additional therapies during the posttreatment period; as a result, no cows were removed from the trial.

\section{DISCUSSION}

Oxytetracycline and tetracycline are often used for intrauterine therapy in metritis (P. J. Gorden, unpublished data) because they are from a broad-spectrum class of antibiotics that inhibits growth in populations of bacteria by binding the $30 \mathrm{~S}$ ribosomal subunit. Oxytetracycline is bacteriostatic, with a spectrum of activity that includes aerobic and anaerobic bacteria commonly found in the postpartum intrauterine environment (Papich and Riviere, 2009). The current grade "A" testing guidelines, described in Appendix $\mathrm{N}$ of the $\mathrm{PMO}$, do not require routine evaluation of raw milk for tetracycline-class antibiotic residues before processing, different from the requirements for $\beta$-lactam antibiotics (US FDA, 2013).

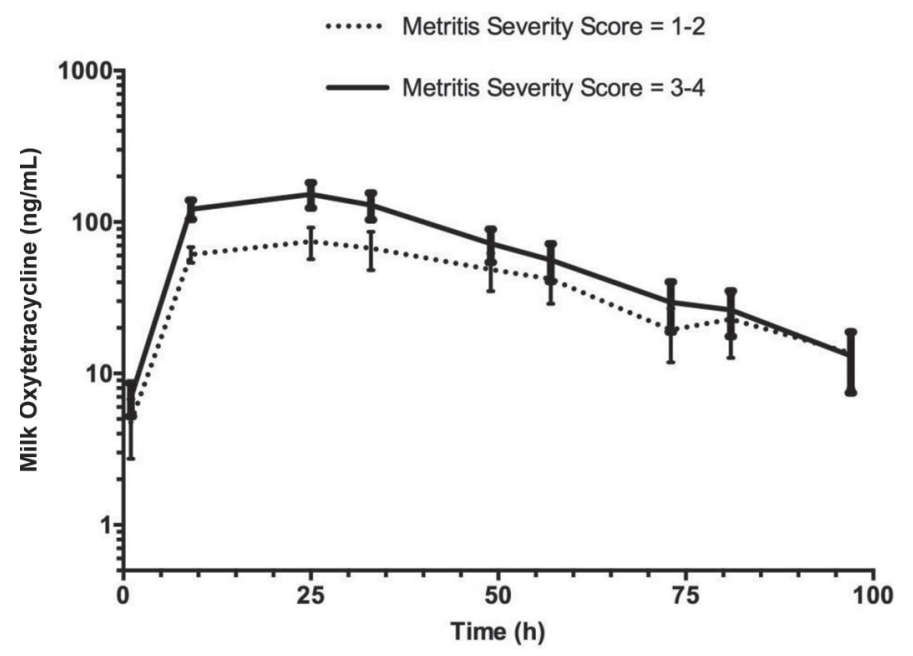

Figure 2. Log transformations of mean $( \pm \mathrm{SE})$ of milk oxytetracycline concentration for cows with initial metritis severity score 1 or 2 versus cows with initial score 3 or 4 following a single intrauterine administration of $4 \mathrm{~g}$ of oxytetracycline hydrochloride. 
The National Conference on Interstate Milk Shipments is a program that milk control agencies from all 50 states, the District of Columbia, and US trust territories participate in. This program makes recommendations, in accordance with the US Food and Drug Administration, for changes to the PMO during its biennial conference. At the 2015 meeting, proposal 211 was passed, requiring the development of a more comprehensive milk residue-testing program in Appendix $\mathrm{N}$ of the PMO, starting with the 2015 version of the PMO (US FDA, 2015a). In April 2015, the US FDA released "Multicriteria-Based Ranking Model for Risk Management of Animal Drug Residues in Milk and Milk Products," which was designed to be a science-based model to assist with future decisions about testing for drug residues in milk-testing programs (US FDA, 2015b). Based on outcomes of the risk-ranking model, future milk-testing requirements may include regular testing for tetracycline-class (tetracycline, OTC, and chlortetracycline) drug residues in raw milk. The current tolerance for tetracycline-class drugs in raw milk is $300 \mathrm{ng} / \mathrm{mL}(\mathrm{ppb})$ and is unique in that it is for the sum of all drug residues for the class (US FDA, 2005). However, some milk processing centers may be testing for tetracycline-class drugs at much lower levels than the United States tolerance to meet regulatory requirements for export.

Our objective was to determine the accumulation and depletion of OTC in plasma and milk following intrauterine administration in an attempt to provide veterinary practitioners with some withdrawal guidelines if this therapy is prescribed. An additional objective was to correlate OTC concentrations with metritis severity scores. It would be prudent for practitioners to recommend testing all milk from cows treated in this manner to prevent the introduction of OTC residues into saleable milk. Currently, the Charm II Tetracycline Test (Charm Sciences Inc., Lawrence, MA) is the only test kit currently approved by the FDA and accepted by the National Conference on Interstate Milk Shipments for testing raw milk for tetracycline-class drugs (US FDA, 2012). The sensitivity of the Charm II test for OTC is 119 ppb (NMPF, 2016). Applying this level of detection against our results, 10 of 32 milk samples would have been positive on the Charm II test $1 \mathrm{~d}$ after treatment. Following this through to the end of the trial, 4 of 32, 1 of 32 , and 0 of 32 samples would have been positive at d 2,3, and 4, respectively. However, due to the cost, sophistication, and limited availability of the Charm II system, it is unlikely to be adopted at the farm level for use on individual cows.

Proposal 211 states that at least 2 approved test kits must be available before a new drug-testing protocol can be enacted. Therefore, in order for tetracycline resi- due testing to occur on a regular basis, at least 1 more approved test kit needs to be available to complete required residue surveillance (US FDA, 2015a). Other more portable bulk tank test kits are available and could be used by farms to test milk from cows treated with intrauterine OTC. However, the tests range in sensitivity from 6 to $1,000 \mathrm{ppb}$, with most sensitivities between 50 and $150 \mathrm{ppb}$ (NMPF, 2016). Applying a 50-ppb sensitivity to our data, 26 of 32,13 of 32 , 3 of 32 , and 2 of 32 cows would have tested positive at d 1 through 4, respectively. Many dairy producers are accustomed to these types of test kits to screen treated cows for antimicrobials, even though the kits are designed for tanker truck samples, not individual cows. Therefore, the selection of test kits on many dairy farms may be dictated by what test kit equipment the farm already has in place. Dairy producers work must with veterinarians and dairy field staff to make sure they select a test kit with appropriate sensitivity for use on individual cows to ensure that milk is being tested at or below the established tolerance for the drug in question.

Several papers have described tetracycline-class depletion from milk, but only 4 have reported results with similar levels of sensitivity to ours (Anderson et al., 1995; Dinsmore et al., 1996; Martin-Jimenez et al., 1997; Haskell et al., 2003). Of those, Anderson et al. (1995) used clinically normal postpartum cows; Dinsmore et al. (1996) used cows with retained placentas and monitored the severity of disease based on rectal temperature. In the present study, cows with higher initial metritis severity scores had higher milk OTC concentration early in the trial period. Tissue inflammation results in increased blood flow to the affected area. We hypothesize that increased milk OTC concentrations in cows with higher initial metritis severity scores was due to increased blood flow to the uterus associated with the inflammatory process and the breakdown of epithelial barriers, increasing the rate and extent of OTC absorption following intrauterine infusion.

Dinsmore et al. (1996) reported no significant difference in OTC concentrations in cows with high rectal temperatures $\left(\geq 39.7^{\circ} \mathrm{C}\right)$ compared to cows that did not develop a fever. However, Benzaquen et al. (2007) showed that 55 of 94 cows with puerperal metritis did not develop a rectal temperature $\geq 39.4^{\circ} \mathrm{C}$, indicating that rectal temperature is not a sensitive indicator of metritis severity. Compared with our results, Dinsmore et al. (1996) reported higher Cmax concentrations in milk following treatment (316.9 vs. $136.1 \mathrm{ppb})$, but they used a higher dose of OTC ( $5 \mathrm{~g})$ and all cows received at least 2 treatments, with a mean of 4.4 infusions/cow. In their study, it took an average of 52.3 $\mathrm{h}$ after the last infusion for milk OTC concentrations 
to drop below the limit of detection of $30 \mathrm{ppb}$, with a maximum time of $144 \mathrm{~h}$.

Our results are similar to data reported previously by Anderson et al. (1995). The present study determined a slightly lower Cmax in milk (136.1 vs. $201 \mathrm{ng} / \mathrm{mL}$ ) despite similar depletion profiles. It is possible that we blunted our Cmax, because we sampled only 2 of 3 milkings per day. Anderson et al. (1995) reported a Cmax at T12 h. In comparing the milk OTC accumulation curve of our data to theirs, it is likely that the true Cmax in our study was higher than that reported by Anderson et al (1995). The recommendation made by Anderson et al. (1995) was to withhold milk from cows with intrauterine OTC for $120 \mathrm{~h}$ to achieve average milk residues below $30 \mathrm{ppb}(\mathrm{ng} / \mathrm{mL})$, which was the established safe level at that time.

In a Food Animal Residue Avoidance Databank (FARAD) Digest article, Haskell et al. (2003) recommended a milk withdrawal time of $72 \mathrm{~h}$ following intrauterine infusion of up to $2 \mathrm{~g}$ of OTC. Additionally, FARAD's online Withdrawal Interval Recommendations indicate that milk should be withheld for $196 \mathrm{~h}$ after intrauterine infusion of 4 to $6 \mathrm{~g}$ of OTC. For both doses, FARAD recommends that milk from individual cows be tested for the presence of violative residues using an appropriate residue-screening test (FARAD, 2015).

Several variables in this trial may be considered weaknesses that were beyond our control due to farm management's stipulations about our trial design. The first was that OTC was found in the plasma of 11 cows at T0. This was likely due to a delay in getting the blood sample collected at initial treatment, because the research personnel were following the hospital crew and had to wait to collect blood until after the treatment was administered. The second involved the farm's administration of systemic ceftiofur to some of the trial cows. The administration of ceftiofur showed no correlation with initial or subsequent metritis severity score, indicating a lack of application of defined clinical parameters guiding ceftiofur use for metritis on the farm. Because we observed no correlation between ceftiofur use and any of the plasma or milk OTC levels, it likely had little effect on our results.

It was our bias before the initiation of the study that hospital personnel at the trial farm were treating many more cows for metritis than was clinically warranted. We confirmed this understanding, because 13 of the 32 cows $(40 \%)$ had a clinically normal metritis severity score at the initiation of therapy. Additionally, 8 of the $21(38 \%)$ cows that received systemic ceftiofur had clinically normal metritis severity scores. Inclusion of rectal temperature may have improved the initial clinical assessment of trial animals done by the farm's personnel. However, on large dairy farms such as this one, manually collecting rectal temperature data on a large number of fresh animals delays the treatment and release of animals from headlocks. This, in turn, can lead to more problems commonly associated with postpartum cows (e.g., heat stress or lameness), and rectal temperature measurement was not implemented on the trial farm. This finding highlights the importance of improved and ongoing training of farm personnel on proper clinical therapies, including identification of animals that truly need treatment. This is especially important because the majority of antimicrobial agents administered to dairy cattle in the United States are not directly administered by veterinarians (P. J. Gorden, unpublished data).

Our results indicate that OTC residues can persist in some cows for up to $96 \mathrm{~h}$ following intrauterine infusion. Our data also suggest that cows with greater initial metritis severity scores absorb more OTC into the systemic circulation from the uterus than cows with lower severity scores. Although some research trials have shown no benefit to intrauterine therapy over on-label systemic treatments (Smith et al., 1998; Drillich et al., 2001) and many veterinarians no longer recommend its use, at least 1 survey has indicated that more than $50 \%$ of farms practiced intrauterine therapy on at least some metritis cases (P. J. Gorden, unpublished data). Because intrauterine OTC therapy is still practiced in some parts of the United States, our objective was to report the depletion of OTC from plasma and milk following intrauterine infusion and not to debate the efficacy or legality of intrauterine therapy for metritis. Intrauterine therapy with OTC is an extra-label therapy; veterinarians prescribing it must determine sufficient withdrawal periods for milk from treated cows to avoid development of violative residues in saleable milk. Residue-screening tests should be used to assist in determining withdrawal times. The results of this study will assist veterinarians in determining appropriate milk withdrawal periods for commonly infused antimicrobials in dairy cows, which is critical, because routine testing of milk for tetracycline residues may occur in the near future.

\section{ACKNOWLEDGMENTS}

This trial was funded by Iowa State University College of Veterinary Medicine (Ames).

\section{REFERENCES}

Anderson, K. L., W. A. Moats, J. E. Rushing, D. P. Wesen, and M. G. Papich. 1995. Potential for oxytetracycline administration by three routes to cause milk residues in lactating cows, as detected by radioimmunoassay (Charm II) and high-performance liquid chromatography test methods. Am. J. Vet. Res. 56:70-77. 
Benzaquen, M. E., C. A. Risco, L. F. Archbald, P. Melendez, M. J. Thatcher, and W. W. Thatcher. 2007. Rectal temperature, calving-related factors, and the incidence of puerperal metritis in postpartum dairy cows. J. Dairy Sci. 90:2804-2814.

de Boer, M. W., S. J. LeBlanc, J. Dubuc, S. Meier, W. Heuwieser, S. Arlt, R. O. Gilbert, and S. McDougal. 2014. Invited review: Systematic review of diagnostic tests for reproductive-tract infection and inflammation in dairy cows. J. Dairy Sci. 97:3983-3999.

Dinsmore, R. P., R. D. Stevens, M. B. Cattell, M. D. Salmon, and S. F. Sundlof. 1996. Oxytetracycline residues in milk after intrauterine treatment of cows with retained fetal membranes. J. Am. Vet. Med. Assoc. 209:1753-1755.

Drillich, M., O. Beetz, A. Pfutzner, M. Sabin, H. J. Sabin, P. Kutzer, H. Nattermann, and W. Heuwieser. 2001. Evaluation of a systemic antibiotic treatment of toxic puerperal metritis in dairy cows. J. Dairy Sci. 84:2010-2017.

FARAD. 2015. Withdrawal interval (WDI) recommendations. Accessed Oct. 15, 2015. http://farad.org/.

Goshen, T., and N. Y. Shpigel. 2006. Evaluation of intrauterine antibiotic treatment of clinical metritis and retained fetal membranes in dairy cows. Theriogenology 66:2210-2218.

Griffin, J. F. T., P. J. Hartigan, and W. R. Nunn. 1974. Non-specific uterine infection and bovine fertility. I. Infection patterns and endometritis during the first 7 weeks post-partum. Theriogenology 1:91-106.

Haskell, S. R. R., R. Gehring, M. A. Payne, A. L. Craigmill, A. I. Webb, R. E. Baynes, and J. E. Riviere. 2003. FARAD Digest. Update on FARAD food animal drug withholding recommendations. J. Am. Vet. Med. Assoc. 223:1277-1278.

Kaneene, J. B., P. H. Coe, J. H. Smith, P. Rapnicki, C. L. Smith, B. Gerloff, and D. A. Morrow. 1986. Drug residues in milk after intrauterine injection of oxytetracycline, lincomycin-spectinomycin, and povidone-iodine in cows with metritis. Am. J. Vet. Res. 47:1363-1365.

Markusfeld, O. 1987. Periparturient traits in seven high dairy herds: Incidence rates, association with parity, and interrelationships among traits. J. Dairy Sci. 70:158-166.

Martin-Jimenez, T., A. L. Craigmill, and J. E. Riviere. 1997. FARAD Digest. Extralabel use of oxytetracycline. J. Am. Vet. Med. Assoc. 211:42-44.

National Milk Producers Federation. 2016. Milk and dairy beef residue prevention manual-Producer manual of best management practices. Accessed January 17, 2016. http://www.nationaldairyfarm. $\mathrm{com} /$.

NRC. 2001. Nutrient Requirements of Dairy Cattle. 7th rev. ed. Natl. Acad. Sci., Washington, DC.

Palenik, T., R. Dolezel, J. Kratochvil, S. Cech, J. Zajic, Z. Jan, and M. Vyskocil. 2009. Evaluation of rectal temperature in diagnosis of puerperal metritis in dairy cows. Vet. Med. (Praha) 54:149-155.
Papich, M. G., and J. E. Riviere. 2009. Tetracycline antibiotics. Pages 895-913 in Veterinary Pharmacology and Therapeutics. 9th ed. J. E. Riviere and M. G. Papich, ed. Wiley-Blackwell, Ames, IA.

Sannmann, I., S. Arlt, and W. Heuwieser. 2012. A critical evaluation of diagnostic methods used to identify dairy cows with acute postpartum metritis in the current literature. J. Dairy Res. 79:436-444.

Sheldon, I. M., J. Cronin, L. Goetze, G. Donofrio, and H. J. Schuberth. 2009. Defining postpartum uterine disease and the mechanisms of infection and immunity in the female reproductive tract in cattle. Biol. Reprod. 81:1025-1032.

Sheldon, I. M., and H. Dobson. 2004. Postpartum uterine health in cattle. Anim. Reprod. Sci. 82-83:295-306.

Smith, B. I., G. A. Donovan, C. Risco, R. Littell, C. Young, L. H. Stanker, and J. Elliott. 1998. Comparison of various antibiotic treatments for cows diagnosed with toxic puerperal metritis. J. Dairy Sci. 81:1555-1562.

US FDA (Food and Drug Administration). 1996. Extralabel drug use in animals. Fed. Regist. 61:57732-57746.

US FDA (Food and Drug Administration). 2005. M-I-05-5: Tolerance and/or safe levels of animal drug residues in milk. Accessed October 8, 2015. http://www.fda.gov/Food/GuidanceRegulation/ GuidanceDocumentsRegulatoryInformation/Milk/ucm077350. htm.

US FDA (Food and Drug Administration). 2012. M-a-85 (revision 14): Beta lactam and other test methods for use under Appendix $\mathrm{N}$ and Section 6 of the Grade "A" Pasteurized Milk Ordinance (PMO). Accessed October 8, 2015. http://www.fda.gov/food/ guidanceregulation/guidancedocumentsregulatoryinformation/ milk/ucm2007975.htm.

US FDA (Food and Drug Administration). 2013. Pasteurized Milk Ordinance, 2013 revision. Accessed October 8, 2015. http://www. ncims.org/2013\%20PMO-FINAL\%20(1).pdf.

US FDA (Food and Drug Administration). 2015a. IMS-a-50: Actions of the 2015 National Conference on Interstate Milk Shipments. Accessed January 17, 2016. http://www.idfa.org/docs/defaultsource/d-news/ims-a-50.pdf.

US FDA (Food and Drug Administration). 2015b. Multicriteria-based ranking model for risk management of animal drug residues in milk and milk products. Accessed October 8, 2015. http://www. fda.gov/Food/FoodScienceResearch/RiskSafetyAssessment/ ucm443549.htm.

Wenz, J. R., D. A. Moore, and R. Kasimanickam. 2011. Factors associated with the rectal temperature of Holstein dairy cows during the first 10 days in milk. J. Dairy Sci. 94:1864-1872.

Williams, E. J., D. P. Fischer, G. C. W. England, H. Dobson, D. U. Pfeiffer, and I. M. Sheldon. 2005. Clinical evaluation of postpartum vaginal mucus reflects uterine bacterial infection and the inflammatory response to endometritis in cattle. Theriogenology 63:102-117. 